Journal of Economics and Behavioral Studies

Vol. 6, No. 8, pp. 647-657, August 2014 (ISSN: 2220-6140)

\title{
Investment Cash Flow Sensitivity as a Measure of Financing Constraints: Evidence from Selected African Countries
}

\author{
Letenah Ejigu Wale \\ College of Economics and Management Sciences, University of South Africa (UNISA), South Africa \\ etalem2000@yahoo.com
}

\begin{abstract}
The use of investment cash flow sensitivity as a measure of financing constraints is an unresolved research agenda. This paper endeavors to explain the conflicting evidence by using proxies for both internal financial constraint and external financial constraint measures. Data is taken from selected six African countries, a region where no previous studies are conducted. It is observed that the investment curve is Ushaped when firms are classified on the basis of internal financial constraint measure (i.e. cash flow). Using external financial constraint proxies (age, size and payout) it is found that all category of firms show positive and significant investment cash flow sensitivity. This suggests that the sampled African firms are externally financial constrained. It is concluded that the way firms are a priori classified as internal vs. external financial constrained matters. This raises the issue of whether the term financial constraints itself is a multidimensional construct.
\end{abstract}

Keywords: Investment Cash Flow Sensitivity, Financing Constraints, African Countries, GMM

\section{Introduction}

The issue of financing constraints has been on the research agenda of academics for a long period. The extant literature tried to ascertain the causes and effects of financing constraint, however measuring the concept of 'financing constraints' itself is still unresolved research agenda (Silva and Carreira, 2012). Beyond the interest of academicians, the issue is also highly relevant to policy makers and practitioners. Many firms around the world complain of financing constraints as a serious impediment to undertake new investments. Empirical evidence by Musso and Schiavo (2008) for France and by Cowling and Mitchell (2003) for the United Kingdom shows that financing constraints has a serious impact on firm survival and many firms exit out of the market due to financing constraints. In the past, many attempts were made by different authors to measure firm-level financing constraints (Silva \& Carreira, 2012). Some of these measures include indirect measures such as the different cash flow sensitivities, direct measures such as company reports, selfevaluation survey data and the use of indexes. The different cash flow sensitivities are further classified as investment-cash flow sensitivities (ICFS), growth-cash flow sensitivities (GCFS) and cash-cash flow sensitivities (CCFS). Silva and Carreira (2012) are of the view that no measure is better than the other because each measure has its own shortcomings. Despite the criticism to all measures, these authors are of the view that the ICFS, as developed by the seminal contributors to this field, Fazzari, Hubbard and Peterson (1988), is the leading approach used in the measurement of financing constraints, and many authors have tested its validity in a variety of settings.

The basic idea of Fazzari et al. (1988) in using ICFS as a measure of financing constraints is as follows. Due to market imperfections (such as information asymmetry and agency costs), external finance will be more costly than internal finance. As a result of such cost differentials, financially constrained firms (firms with low dividend payout as per their classification) will be in a difficult position to raise external finance, or if they do so, higher costs need to be incurred. As a result, these firms will show a natural tendency to rely on internal finance to finance their investment. This again means their investment will show a positive and significant sensitivity to their internal cash flow. If their internal cash flow increases, they will invest more; if it decreases they will cut new investment projects. On the other hand, firms that are not financially constrained (firms with high dividend payout) can raise external finance easily and their investment will not show sensitivity to the availability of internal cash flow. In this way, ICFS can be used as a measure of financing constraint. Even if ICFS is the leading framework and widely used by many authors, it is highly contested on 
both theoretical and empirical grounds. The most significant challenge comes from Kaplan and Zingales (1997), Cleary (1999), Alti (2003) the detail of which is to be discussed in the upcoming literature review section. On the whole, the issue of measuring financing constraint is still an open question. This research will add to this contested literature by testing the empirical plausibility of using ICFS as a framework for measuring financing constraint.

Cleary, Povel and Raith (2007) and Guariglia (2008) attempted to reconcile the conflicting findings by classifying firms a priori using internal and external financial constraint measures. Using their insight the current research contributes to this reconciliation literature using African firms' data which is not studied till now. Furthermore, the African region is selected because the financing constraint faced by firms differs across countries and regions and it depends on the different institutional and country level characteristics in which Africa is different. Specifically authors such as Love (2003) and Khurana, Martin and Pereira (2006) have shown that the financing constraints firms face depend on the financial development of a country. Africa has weak financial development status compared to other parts of the world and hence many firms in Africa are expected to be financially constrained as opposed to other parts of the world. One purpose of the paper is to check whether this sort of evidence can be observed in African countries. The rest of this paper provides a discussion of the relevant literature, the methodology, results and discussion and concluding remarks.

\section{Literature Review}

As highlighted in the introduction, ICFS is the leading framework used by many authors to investigate the issue of financing constraints and Fazzari et al. (1988) are credited with the theoretical and empirical framework of the measure. Since their seminal paper, a large literature has flourished and concerns started to rise about the validity of using ICFS as a measure of financial constraints (see Hubbard, 1998; Carreira \& Silva, 2010; Silva \& Carreira, 2012 for a survey of this large literature). The major challenge comes from Kaplan \& Zingales (1997). They argue that the theoretical predictions are ambiguous. Besides in the empirical result, the claim that dividend paying firms are less constrained is not tenable. They claim that firms classified a priori as financially less constrained, using a measure of firm liquidity, even show high ICFS. This same result is also found by Cleary (1999). Fazzari Hubbard and Peterson (2000) responded to such claim of Kaplan and Zingales (1997) and the debate further intensified. Kaplan and Zingales (2000) also responded to such view. Some authors such as Allayannis and Mozumdar (2004), Cleary et al. (2007), Guariglia (2008) tried to explain such contrasting results. Allayannis and Mozumdar (2004) said the result of Kaplan \& Zingales (1997) is driven by influential observations. Furthermore, they argue that negative cash flows drive the result of Cleary (1999).

Cleary et al. (2007) has gone much further to explain the contrasting empirical findings. They developed a theoretical model and tried to differentiate the effect of different ways of classifying firms in a priori sense. The two widely used ways of classifying firms in such sense are internal financial constraint measures and external financial constraint measures. They empirically tested the model and found that the sensitivity is determined by the interaction of a cost and revenue effect. The cost effect predicts a positive relationship between cash flow and investment. Under such effect firms use internal funds to finance their investment rather than resorting to external borrowing. They do so because the loan repayment will be greater than the revenue generated from the additional investment made through debt finance. In such setting the risk of default on the loan will be high and firms will refrain from borrowing from external sources. On the other hand, the revenue effect predicts negative relationship between cash flow and investment. It works quite opposite to the cost effect. Under such conditions the loan repayment will be greater than the revenue generated from the additional investment made through debt finance. The risk of default on the loan will be low and firms will borrow. As a result, their reliance on internal finance will be less.

The prediction of Cleary et al. (2007) model is as follows. If firms are classified based on internal financial constraint measures such as internal funds, the investment curve will be U-shaped in relation to cash flow. The negative relationship in the curve will be dominated by firms having negative (low) cash flow whereas the positive relationship will be dominated by firms having large positive cash flow. However, if firms are classified based on external financial constraints measures such as size, age and payout, investment will show either positive or negative relationship with cash flow. The sign of the relationship will be determined by the 
strength of the cost effect or revenue effect. The cost effect will dominate if negative cash flows are few or absent whereas the revenue effect will dominate if there are many firms with negative (low) cash flows. External financial constraints are created due to capital market imperfections. Two of the most noted capital market imperfections that arise between the capital provider (investor) and the firms are information asymmetry and agency costs. Proxies used for external financial constraints include firm age, size and payout. Bernanke, Gertler and Gilchrist (1996) are of the view that much of the external capital constraints of small and young firms are explained by information asymmetry. It is difficult to get reliable and less costly information about the operation of these firms. Similarly firms with low dividend payout are subject to information asymmetry and face external financial constraints because the market views lack of dividend payment as a bad signal of the firms' future prospect (Bhattacharya, 1979)

Based on the insights from the substantial contribution of Cleary et al. (2007), Guariglia (2008) in her study of UK firms showed that the different results arise due to the way firms are a priori classified as financially constrained or not. She explained that most authors who classified firms a priori based on external financial constraints measures (such as firm age, size and payout) produce results consistent with Fazzari et al. (1988). Some exceptions are Kadapakkam, Kumar and Riddick (1998) and Cleary (2006). They found that larger firms and firms with higher dividend payout have higher investment cash flow sensitivity. On the other hand, authors who classify firms based on internal financial constraint measures (such as cash flow or related measures of firm liquidity) produce results consistent with the research traditions in Kaplan \& Zingales (1997). This indicates the way firms are classified a priori matters. But she also is of the view that the different financial constraints measures may be related and may not yield different findings. Firms with greater internal cash flow (a measure of internal financial constraint) may not be in difficult position to raise external finance as lenders view these firms as less risky. On the other hand internally constrained firms are perceived as risky and their capability to raise external finance will be limited.

In sum, the review showed that investment cash flow sensitivity is the dominant framework used to measure firm level financial constraint. But the empirical evidence in test of this framework shows contrasting results. Some authors find financially constrained firms shows higher investment cash flow sensitivities whereas others find that firms which are least financially constrained shows higher sensitivity. More recent evidence shows that the way firms are classified as financially constrained or not may have a bearing on the observed conflicting empirical result. However, there is also a counter argument in that the way firms are classified may not matter as such due to the correlation between the different ways of classifying firms. Such latter claim is not investigated using clear theoretical framework. With this above summary of the literature review, the contributions of this paper are three-fold. First, based on the insight of Cleary et al. (2007) and Guariglia (2008), it tests the effect of internal and external financial constraint measures on the investment cash flow sensitivity coefficient using African data, a region not studied till now. Specifically, by using the internal financial constraint measure, it tests whether the investment curve is U-shaped. The theory of U-shaped investment curve is not tested by many empirical studies. Second, based on the insight of Cleary (2006) it extends the literature a bit by showing the relationship among the financial constraints measures using correlation coefficients. It is felt that a closer look is needed on the relationship between the various financial constraint measures to determine whether ICFS can really be used as a measure of financing constraint. Third, beyond reconciling the different conflicting findings, the paper interprets the substantive meaning of the results to conclude whether ICFS can really be used as a measure of financing constraints.

\section{Methodology}

Firm level data is collected from Orbis, a financial database maintained by the Bureau van Djik. Orbis contains information on 60 million companies around the world and over 260,000 companies in the African continent. The information includes descriptive, information, company financials, news, market research, ratings, country reports, ownership and merger and acquisition data. For this research, company financial data extracted from the balance sheet and income statement are used. Six African countries claimed to have high level of financial development are taken as a sample. These include Egypt, Kenya, Morocco, Nigeria, South Africa and Tunisia (Starkey, 2010).Countries with high financial development are taken as a sample because some studies such as those by Love (2003) and Khurana et al (2006) showed that financial development ease firm level financing constraints. Thus implicitly it is expected that firms existing in such African countries are 
assumed to be less financially constrained as opposed to other African countries having less financial development. Consistent with prior studies on investment cash flow sensitivity, data is taken from manufacturing companies only. These are firms with primary code of NACE Rev 2 from 10-32. These includes manufacturing of food products, beverages, tobacco, textile, wearing apparel, leather, wood products, paper, printing, coke and refined petroleum, chemicals, pharmaceuticals, rubber \& plastic, non-metallic mineral products, basic metal, fabricated metal, computer electronics and optical products, electrical products, other transport equipment and other manufacturing.

The total population of manufacturing firms in each country is as follows: Egypt $(3,928)$, Kenya (475), Morocco (41,992), Nigeria (856), South Africa $(24,036)$, and Tunisia $(2,051)$. In terms of time dimensions, firms level data is available for a period of 10 years (from 2004-2013). But due to data cleaning, this data is reduced to 7 years (from 2005-2011). Furthermore the actual sample size used from the six countries is reduced to 273 firms. With data available for an average of 6 years, a total of 1574 firm-year observations constitute the total sample size. However, the number of firms-year observations is further reduced to 854 due to the use of Generalized Method of Moments (GMM) estimation. The country-wise distribution of the sample shows that Egypt and South Africa have the highest number of firms (98 and 94 firms respectively) whereas the rest countries are least represented. Especially Kenya and Tunisia has only 12 and 6 firms respectively. With time dimensions, Tunisia has the full 7 year data (from 2005-2011) whereas Nigeria and Kenya have 5 years data. The following data cleaning strategies are followed. First, consistent with Baum, Schafer and Talavera (2011) firms that are engaged in significant Merger and Acquisition (M \& A) and divestiture activities are removed. The growth rate of assets is calculated and if a firm-year observation has a growth rate that exceed 85\%; it was trimmed (removed) from the dataset. These firms are excluded because firms' growth as a result of $M \& A$ and divestiture activities are not considered as normal. It will distort the estimated relationship between investment and cash flow. Second, all firm level variables are winsorized at the $1 \%$ and $99 \%$ percentile i.e. all outliers are replaced with these percentile values. This procedure is employed to reduce the potential impact of outliers on parameter estimates. Third, those firms-year observations with negative assets values are dropped. Such kind of data is unusual.

Econometric Model: Two models are used to estimate the ICFS coefficients: the Q model and Euler Equation approach (George, Kabirb \& Qianc, 2011). The Q model has the advantage of measuring directly the expected value of future profitability. But the $Q$ model is not good if stock market prices are not efficient. Secondly, average $Q$ is frequently used in the literature but it can be imprecise proxy for marginal $Q$ (the value of an additional unit of new capital). Furthermore, the use of $Q$ may overestimate the cash flow sensitivity coefficient because cash flow may contain information about investment opportunities that were not captured by Q (Carreira \& Silva, 2013).In a model where financial frictions are absent, Alti (2003) showed that even if Q is corrected firms exhibit positive ICFS. Guariglia (2008) is also of the view that the Q-model suffers from misspecification problems. The Euler equation model exploits the relationship between investments in successive time periods and has the advantage that it doesn't require explicit use of future values. In view of the shortcomings of the $Q$ model, this paper uses the Euler equation approach. Taking insights from Carreira \& Silva (2013) and Guariglia (2008) and modifying a bit, the basic econometric model that tests for the sensitivity of investment to cash flow looks like this:

$$
\left(\frac{I_{i t}}{K_{i t-1}}\right)=\alpha+\beta_{1}\left(\frac{I_{i t-1}}{K_{i t-2}}\right)+\beta_{2} \Delta S+\beta_{3}\left(\frac{C F_{i t}}{K_{i t-1}}\right)+f_{i}+d_{c}+d_{t}+e_{i t}
$$

Where $I$ is investment measured as the difference between net property, plant and equipment at the end of the period and beginning of the period plus depreciation; $K$ is the capital stock or net property, plant and equipment, $\Delta S$ is the natural logarithm of sales growth; $C F$ is cash flow measured as Net Income + Depreciation; fi represents firm fixed effects, $d c$ represents country dummies and $d t$ represents time dummies. Time dummies are added because firm level investment is influenced by macroeconomic factors such as the business cycle. Finally, eit is the error term. In the next equation 2, the cash flow variable is interacted with Firm Classification $(F C)$. Firms are classified by internal financial constraint measure (cash flow) and external financial constraint measure (age, size and payout). Dummy variables of these firm categories are created. 


$$
\left(\frac{I_{i t}}{K_{i t-1}}\right)=\alpha+\beta_{1}\left(\frac{I_{i t-1}}{K_{i t-2}}\right)+\beta_{2} \Delta S+\beta_{3}\left(\frac{C F_{i t}}{K_{i t-1}}\right)+\beta_{4}\left(\frac{C F_{i t}}{K_{i t-1}}\right) *(F C)+f_{i}+d_{c}+d_{t}+e_{i t}
$$

The purpose of the cash flow interaction terms with internal and external financial constraints measures is to check whether the way firms are a priori classified into financial constraints groups matter for the investment cash flow sensitivity coefficients. To create the dummies for internal and external financial constraints, two procedures are used. First, the proxies for internal financial constraints (cash flow) and external financial constraints (age, size and payout) are split using quartile values. Second, a dummy variable is created for the data spanning the different quartile values.

The quartile based classification of firms is used by many authors in the literature. However, it is conceived that a different result might be produced if another way of classifying firms was used. Specifically theoretical and logical way of classifying firms is better than the adhoc quartile based classification which is dependent on the available data. But the problem is there is no clear guidance in the literature on how to classify firms on a theoretical basis. Thus the latter issue is not attempted in this research and readers shall consider this caveat while interpreting the result. As an example of internal financial constraints measured by cash flow, those firm-years below Q1 are classified as low cash flow; firm-years between Q1 and Q3 are classified as medium cash flow; firm-years above Q3 are classified as high cash flow. The same classification scheme is used for other variables. The quartile values for the different variable categories are as follows. For cash flow, the computed Q1 is 0.20 , but it is set to the value of zero, the reason being to study the effect of negative cash flow on the investment cash flow sensitivity coefficient. The Q3 value for cash flow is 1.21. For age, the Q1 and Q3 values are 18 and 55 respectively. For size the values are US\$27,740 and US\$282,058. Finally for dividend payout the values are 0 and 0.44 .

After the variables are split by quartile values, a dummy variable is created as follow. The code 1 is given if a firm is say low cash flow (below Q1 for cash flow), zero otherwise. Then this low cash flow variable will be interacted with the main cash flow variable. The same procedure is used for all other categories of the remaining variables created using quartiles. For dividend payout, low dividend payers are set to be firmyears with a payout ratio of less than or equal to zero. The equality sign is needed because it is difficult to assume negative dividend. As to the estimation technique, the system GMM estimators of Blundell and Bond (1998) are used. Such estimators allow control for fixed effects through first differencing, take into account heteroskedasticity and autocorrelation and the presence of endogenous variables. To address the issues of heteroskedasticity and autocorrelation, robust standard errors are used. Instruments of lag two are used for the right hand side variables. The Sargan test of overidentifying restriction is used to test for instrument validity. The AR (2) test is used to check for autocorrelations in first difference errors.

\section{Results and Discussion}

Table 1: Descriptive Statistics

\begin{tabular}{lllllllllllll}
\hline \multirow{2}{*}{ Variables } & \multicolumn{1}{l}{ Cash flow } & \multicolumn{3}{c}{ Age } & \multicolumn{4}{c}{ Size } & \multicolumn{4}{c}{ Payout } \\
\cline { 2 - 13 } & $\mathbf{L}$ & $\mathbf{M}$ & $\mathbf{H}$ & $\mathbf{Y}$ & $\mathbf{M}$ & $\mathbf{0}$ & $\mathbf{S}$ & $\mathbf{M}$ & $\mathbf{L}$ & $\mathbf{L}$ & $\mathbf{M}$ & H \\
\hline Investment & 0.255 & 0.254 & 1.01 & 0.43 & 0.45 & 0.430 & 0.68 & 0.39 & 0.30 & 0.32 & 0.37 & 0.65 \\
Sales growth & 0.141 & 0.151 & 0.18 & 0.18 & 0.14 & 0.170 & 0.21 & 0.13 & 0.15 & 0.17 & 0.17 & 0.13 \\
Cash flow & -0.5 & 0.410 & 15 & 4.2 & 4.11 & 3.570 & 5.16 & 4.2 & 2.30 & 3.13 & 3.2 & 5.75 \\
Firm-Year (NT) & 128 & 1052 & 394 & 365 & 805 & 404 & 393 & 788 & 393 & 724 & 344 & 506 \\
\hline
\end{tabular}

Descriptive Statistics: The result of the descriptive statistics shows that high cash flow firms have the highest investment and sales growth. These high cash flow firms are less financially constrained and thus they can invest more with internal funds. Coming to the age classification, young firms have the highest sales growth rate and cash flow. The highest sales growth rate for young firms is expected. But investments are a bit higher in medium aged firms probably because young firms are more externally financially constrained. With size, small firms have the highest investment rate, sales growth and cash flow. The high sales growth and cash flow may be expected, but the higher investment rate for small firms is unexpected because they are 
judged as externally financially constrained. On dividend payout, high payout firms have the highest investment and cash flow. Sales growth is high in either low or medium payout firms.

In sum, high cash flow firms, young firms, small firms and high payout firms are the leader in investments, sales growth and cash flow. But this simple statistics suggests a combined picture for financing constraints. If the internal and external financial constraints measures were to be consistent, one should find the following hypothetical and ideal firms that have the highest investment, sales growth and cash flow. The ideal firm is the one that is not internally constrained (high cash flow firm) and not externally constrained (old, large and high payout firm). But the result found is somewhat mixed. The best firms are high cash flow firms from internal classification and young, small and high payout firms from the external classification. The fact that young and small firms are best from the external classification is somewhat odd. This suggests that the various ways of classifying firms among financial constraint groups is inconsistent, an agenda to be pursued in the upcoming correlation section.

Table 2: Correlation Coefficients among the Various FC Measures

\begin{tabular}{lllll}
\hline & Cash flow & Age & Size & Payout \\
\hline Cash flow & 1 & & & \\
Age & 0.0043 & 1 & & \\
Size & $-0.0911^{* *}$ & $0.0767^{* *}$ & 1 & \\
Payout & 0.0519 & 0.0495 & $-0.0742^{* *}$ & 1 \\
\hline ** Significant at $5 \%$ & & &
\end{tabular}

** Significant at $5 \%$

Correlation Coefficients: Cash flow is not significantly correlated with age and payout or weakly negatively correlated to size. Age and size are significantly correlated but their correlation is weak. Age and payout are not correlated. Size is weakly and negatively correlated to payout. In general correlations between the internal and external financial constraint measures or within the external financial constraint measures are non-existent or weak. This suggests that the way firms are classified a priori among the different financial constraint group is an adhoc approach. It needs sound theory and empirical testing. This is suggested for further research. Despite such limitation of using the various financial constraint measures, this research pursues the agenda using them and the next section discusses the econometric results.

Econometric Results: Before interpreting the results, few points are suggested about the model adequacy. The Wald statistics is significant indicating all the included variables jointly explain the investment behavior of firms in the selected African countries. The Sargan test is insignificant indicating the instruments are valid. The AR (2) test is also insignificant indicating there is no autocorrelation in the first difference residuals and thus no specification problem in the model.

Investment equations without interactions: The basic model without interactions is run using lagged investment, sales growth and cash flow as explanatory variables. The result indicated that lagged investment not significant indicating there is no persistence in the investment decision of firms. Current year investment doesn't depend on what happened in last year. Other exogenous factors are affecting investment rather than internal decisions of the firms. Sales growth is also insignificant indicating demand for firms' products is not the driving force behind firms' investment. The main variable of interest to this research is cash flow and it is found to be a positive and significant determinant of firm investment. A 10\% increase in cash flow leads to a $4.4 \%$ increase in firm investment. According to Fazzari et al. (1988), such positive and significant cash flow coefficient shall be interpreted as evidence of financial constraints. According to the Cleary et al. (2007) argument, the positive and significant coefficient of cash flow suggests the cost effect prevails over the revenue effect. The loan repayments are greater than the revenue generated with the additional investment. This increase the risk of default and firms will not borrow. Rather they will realign their investment with their internal funds. 
Table 3: Econometric Results

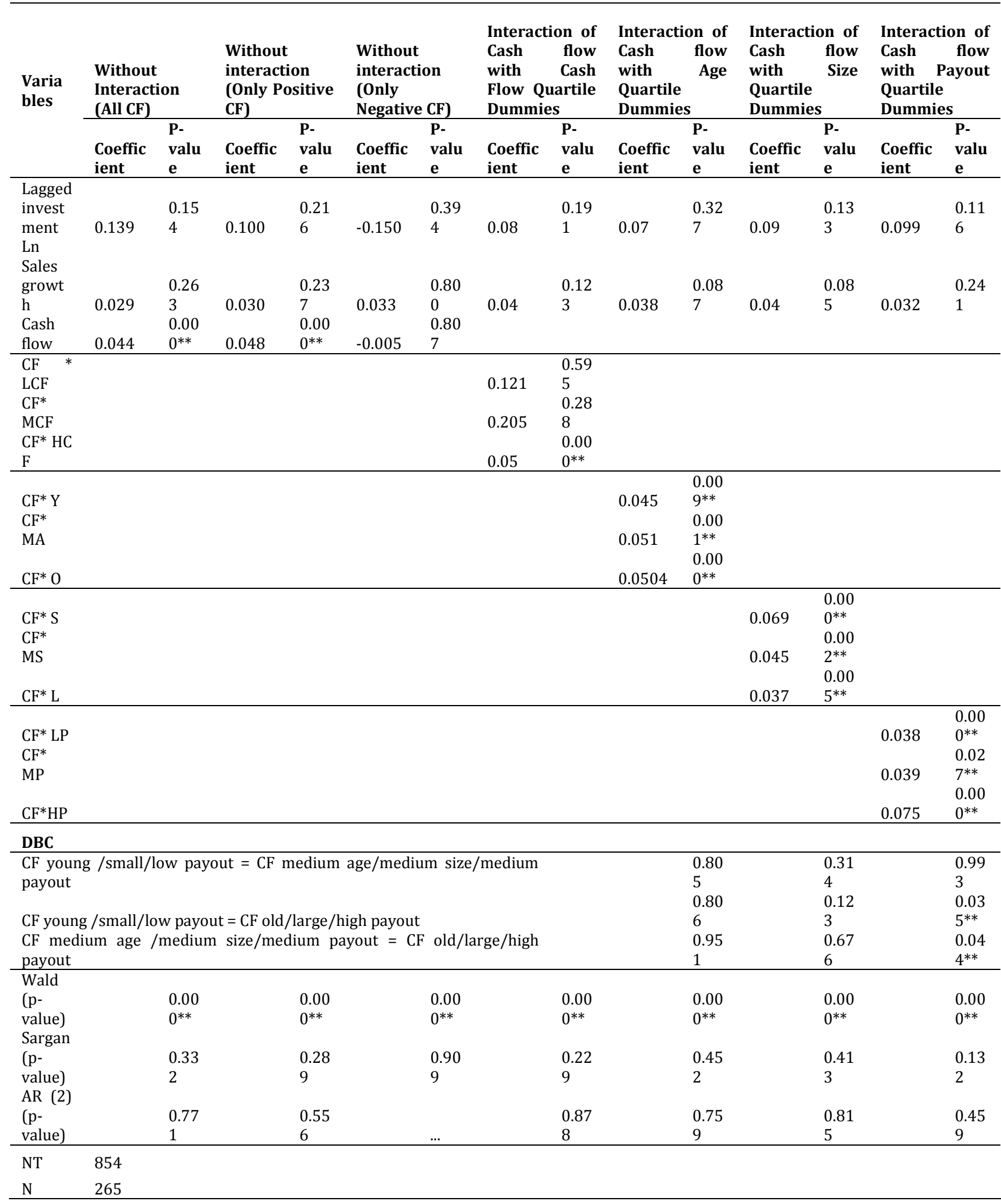

Notes: Country and time dummies are included, but for brevity purpose the result is not reported.

** significant at $5 \%$ 
In the next result section, analysis is made by excluding negative cash flows. The purpose of this analysis to see whether negative cash flows have a distortionary effect on the estimated sensitivities as suggested in Allayannis \& Mozumdar (2004). The estimates show that excluding negative cash flow increased the sensitivities from 0.044 to 0.048 . Although the change is not that much high, this indicates that firms with negative cash flow have lower (possibly negative) investment cash flow sensitivity coefficients than other firms. To confirm the claim of low or negative sensitivities for firms with negative cash flow, regression is run for firms having negative cash flow only. The result although not significant shows a negative coefficient. The lack of significance of these negative cash flows is due to the small number of firms with negative cash flow. In fact out of the total sample of 265 firms used for the GMM estimation, only 35 (13\%) firms have negative cash flow. Despite the insignificant result, the negative coefficient shows the revenue effect dominate over the cost effect. The revenue generated with the additional investment is sufficient to cover the loan repayments. This means the risk of default is low. Hence firms will borrow and don't depend much on their internal funds to finance their investments. Combining the results of all (positive) cash flows and negative cash flow, it can be roughly concluded that the investment curve is U-shaped and the result is consistent with the proposition of Cleary et al. (2007).

Investment equations with interactions based on Internal Financial Constraint Measures: In this section firms are classified based on the internal financial constraints they face (i.e. cash flow) using quartiles and such cash flow dummies are interacted with cash flow. The result shows that only firms with high cash flow have significant and positive investment cash flow sensitivity. The rest interaction terms are not significant. As above it was expected that those firms having negative cash flow would show negative investment cash flow sensitivity. This is not the case it may be because the variable used is an interaction term with cash flow, not the single term cash flow. The insignificant result for the low and medium cash flow firms on the one hand and the significant and positive sensitivity for the high cash flow firms on the other hand shows the result are consistent Kaplan and Zinagles (1997). These authors were of the view that the least constrained firms (i.e. high cash flow firms) show higher investment cash flow sensitivity. Such result was one of the major criticisms of Fazzari et al. (1988) claim that only the constrained firms will show high sensitivity. But it has to be underscored that the ways firms are classified differ among these two classic authors, an issue that will be discussed in the later sections. Combing the result of all firms classified by cash flow, still the U-shaped investment curve of Cleary et al. (2007) seems appealing. To reaffirm this U-shape curve, Table 4 contains a simple statistics showing the relationship between the various percentile values of cash flow and investment. At the median cash flow ratio of 0.46 , the investment ratio reaches to a minimum of 0.19. On either way to the median cash flow ratio, the investment ratio becomes higher. This suggests Ushaped relationship.

Table 4: Is the Investment curve U-shaped?

\begin{tabular}{lll}
\hline $\begin{array}{l}\text { Percentile } \\
\text { Ranges }\end{array}$ & \multicolumn{1}{c}{ Percentiles of CF } & $\begin{array}{l}\text { Mean Investment if CF is } \\
\text { less than X percentile }\end{array}$ \\
\hline $1 \%$ & -1.74 & 0.67 \\
$5 \%$ & -0.11 & 0 \\
$10 \%$ & 0.03 & 0.32 \\
$25 \%$ & 0.2 & 0.24 \\
$50 \%$ & 0.46 & 0.19 \\
$75 \%$ & 1.21 & 0.44 \\
$90 \%$ & 20.37 & 0.44 \\
$95 \%$ & 20.37 & 1.23 \\
$99 \%$ & 20.37 & 1.23 \\
\hline
\end{tabular}

Investment equations with interactions based on External Financial Constraint Measures: Firms are also classified based on the external financial constraints they face. Variables such as age, size and payout are used to classify firms for such purpose. Coming to the interaction of cash flow with various age categories, it is found that all age categories show significant and positive investment cash flow sensitivity. Since external financial constraint measures are used to capture the extent of capital market imperfections and the lack of 
access to external finance for firms, a positive and significant cash flow coefficient shall be interpreted as evidence of financial constraints. Thus the positive and significant cash flow coefficient indicates that all firm age categories are constrained firms. Chi-square tests are conducted to test for significant difference in the sensitivity coefficients between the various age categories. The result shows that there is no statistical difference between the various coefficients in terms of investment cash flow sensitivity. The result for cash flow size interaction is the same as the age interactions. All size categories shows positive and significant investment cash flow sensitivity coefficient indicating all size categories are constrained. The chi-square test shows there is no statistical difference between the various coefficients in terms of investment cash flow sensitivity. Guariglia (2008) in her UK sample found the sensitivities are positive and significant for the young and medium aged firms with the earlier higher than the latter. She doesn't found significant sensitivities for old firms. In the case of firm size she also found higher sensitivities for small and medium sized firms and not for large firms. Our result for younger (smaller) and medium age (medium size) firms is consistent with her findings. But the result for older (larger) firms is in contrast with her result. The fact that older (larger) firms are even constrained in the selected African countries is not that surprising. In many African countries the financial markets are under-developed, and thus most firms face serious financial constraints. The result for dividend payout interaction shows the same story as age and size interaction. All categories shows significant and positive investment cash flow sensitivity coefficient. The chi-square test shows high payout firms have a significantly higher sensitivity than the low and medium payout firms. This is somewhat odd with the findings of Fazzari et al. (1988) who used dividend payout as a classification tool.

Discussion: Consistent with the observations of Fazzari et al (1988) and Kaplan and Zingales (1997), the findings of this paper show that the way firms are classified a priori as financially constrained or not matters. The correlation among the internal and external financial constraint measures are also weak or insignificant as shown in the result of this study and in the study conducted by Cleary (2006). The implication of this is that the concept of financial constraints itself shall be conceptualized as multidimensional construct of both internal and external financial constraints. But without going that much far of multidimensional conceptualization, let us speculate some results that have far reaching consequences. If the way firms are a priori classified matters which criteria should be used to classify firms, internal or external? External criteria are felt to be a good way to classify firms. Internal criteria is narrow because virtually all firms are internal financially constrained, i.e., the investment needs of most firms is greater than their internally generated funds. For this reason they have to raise external finance and external financial constraint measures still serve as better criteria to classify firms. But the odd thing is that these external financial constraint criteria (such as age, size and payout) are not strongly correlated. Thus the search for better external financial constraint criteria is an ongoing debate.

From the above discussion, it is implied that external financial constraint measures are a better conceptualization of the term financial constraint. The result of the study using such conceptualization indicated two things. First, all categories of the sampled African firms are financially constrained. The implication of this result is that financial constraint is really a serious problem for African firms and it confirms the repeated complain of many firms of "access to finance" as a serious constraint for their operation. Financial constraints deter firm investment, firm growth and hinder aggregate economic growth. Financing constraints also endanger firm survival and forces firms to exit out of the market. The weak private sector development and the resulting staggering economic performance of many African countries may be partly attributed to this reason. The second result indicated that all categories of firms are equally constrained and no distinction can be made between the different firm categories in the extent of financial constraints they face. The implication of this result is that classifying firms for financial access is not as such relevant. Much of the literature documented that young and small firms are highly financially constrained than old and large firms. Such literature further suggests that more policy emphasis shall be given to the earlier group of firms. But our result shows such distinction is not relevant as such. This is clearly a unique result of the African continent where financial markets are underdeveloped to curb the financial constraint of at least the relatively informationally better-off old and large firms. But this doesn't seem to happen. 


\section{Conclusion}

This study investigated the use of investment cash flow sensitivity as a measure of financing constraints using African data, a region not studied till now. The result of the study confirms that all categories of firms equally show positive and significant investment cash flow sensitivity using external financial constraint proxies (age, size and payout). This suggests that all firm categories are externally financial constrained and no distinctions can be made among the different firm categories in the extent of external financial constraints they face. On internal financial constraint measures, the study finds that high cash flow firms have higher sensitivity whereas low and medium cash flow firms have no significant sensitivity. Corroborating evidence shows that when firms are classified by internal financial constraints measure (i.e. cash flow) the investment curve looks like U-shaped. Combining the result of using external and internal financial constraint measures, it can be concluded that the way firms are classified a priori (internally financially constrained vs. externally financially constrained) matters a lot and this explains the conflicting findings of previous studies. If this is the case, the following questions need to be clarified by further research using a proper theoretical framework. Is the concept of financial constraint itself one-dimensional or multidimensional? If it is multidimensional, what is the relationship among the various dimensions? Which dimension is more important? Shall investment cash flow sensitivity be retained as a measure of financing constraints or scrapped and be replaced by a priori measures used to classify firms? Our view to such questions is that financial constraints still be conceptualized as one dimension of external financial constraints as virtually all firms are internally constrained. Furthermore, it is viewed that, ICFS shall be retained as a measure of financing constraint with firms classified by external financial constraint measures.

Conceiving external financial constraints as a better conceptualization of the term financing constraints, let us suggest some policy recommendations based on this result. To recall the result of the study using this conceptualization clearly indicate that all categories of the sampled African firms are equally financially constrained. Two policy implications arise out of this result. First, policy makers shall work more on increasing the access to finance of all categories of firms rather than leaning more towards one group of firms to the ignorant of the other. Nevertheless, a distinction among firm groups can still be made for the agenda of "access to finance". The different firm groups can be ranked according to their contribution to economic growth or any other relevant social goal. This latter issue requires its own research. Second, such result is felt to be driven by the low financial development of the African region. The extant literature documented that financial development can curb firm level financing constraints by mitigating capital market imperfections such as information asymmetry and agency costs. Thus more policy emphasis shall be given to financial sector development in Africa. This includes banking sector development and the development of vibrant and liquid stock markets. However, since most of the current financial landscape of many African countries is dominated by informal finance (such as microfinance, cooperative finance, money lenders, rotating saving and credit associations etc) more policy emphasis shall be made in transforming this huge sector or trying to utilize the best out of this sector.

Acknowledgement: I greatly acknowledge the help of editor and technical editor of the Journal, the anonymous reviewers, Daniel Makina (University of South Africa) and Chris Kapp \& Associates for constructive comments.

\section{References}

Allayannis, G. \& Mozumdar, A. (2004). The impact of negative cash flow and influential observations on investment-cash flow sensitivity estimates. Journal of Banking and Finance, 28(5), 901-930.

Alti, A. (2003). How sensitive is investment to cash flow when financing is frictionless? Journal of Finance, $58(2), 707-722$.

Baum, C., Schäfer, D. \& Talavera, O. (2011). The impact of the financial system's structure on firms' financial constraints. Journal of International Money and Finance, 30(4), 678-691.

Bernanke, B., Gertler, M. \& Gilchrist, S. (1996). The financial accelerator and the flight to quality. The Review of Economics and Statistics, 78(1), 1-15.

Bhattacharya, S. (1979). Imperfect information, dividend policy, and the 'bird in the hand fallacy. Bell Journal of Economics, 10(1), 259-270. 
Blundell, R. \& Bond, S. (1998). GMM estimation with persistent data: An application to production functions. Econometric Reviews, 19(3), 321-40.

Carreira, C. \& Silva, F. (2013). Does Size, Age and Dividend Policy Provide Useful Measures of Financing Constraints? New Evidence from a Panel of Portuguese Firms, Estudos Do GEMF, 26

Carreira, C. \& Silva, F. (2010). No Deep Pockets: Some stylized results on firms' financial constraints. Journal of Economic Surveys, 24(4), 731-53.

Cleary, S. (2006). International corporate investment and the relationship between financial constraint measures. Journal of Banking and Finance, 30(5), 1559-1580.

Cleary, S. (1999). The relationship between firm investment and financial status. Journal of Finance, 54(2), 673-692.

Cleary, S., Povel, P. E. \& Raith, M. (2007).The U-shaped investment curve: Theory and evidence. Journal of Financial and Quantitative Analysis, 42(1), 1-39.

Cowling, M. \& Mitchell, P. (2003). Is the small firm's loan guarantee scheme hazardous for banks or helpful to small business? Small Business Economics, 21(1), 63-71.

Fazzari, S., Hubbard, R. \& Petersen, B. (2000). Investment-cash flow sensitivities are useful: a comment on Kaplan and Zingales. Quarterly Journal of Economics, 115(2), 695-705.

Fazzari, S., Hubbard, R. \& Petersen, B. (1988). Financing constraints and corporate investment. Brookings Papers on Economic Activity, 1, 141-206.

George, R., Kabir, R. \& Qian, J. (2011). Investment cash flow sensitivity and financing constraints: Evidence from Indian Business Groups. Journal of Multinational Financial Management, 21(2), 69-88

Guariglia, A. (2008). Internal financial constraints, external financial constraints and investment choice: Evidence from a Panel of UK firms. Journal of Banking \& Finance, 32(9), 1795-1809.

Hubbard, R. (1998). Capital-market imperfections and investment. Journal of Economic Literature, 36(1), 193225.

Kadapakkam, P., Kumar, P. \& Riddick, L. (1998). The Impact of cash flows and firm size on investment: The international evidence. Journal of Banking and Finance, 23(3), 293-320.

Kaplan, S. \& Zingales, L. (2000). Investment-cash flow sensitivities are not valid measures of financing constraints. Quarterly Journal of Economics, 115(2), 707-712.

Kaplan, S. \& Zingales, L. (1997). Do investment-cash flow sensitivities provide useful measures of financing constraints? Quarterly Journal of Economics, 112(1), 169-216

Khurana, I., Martin, X. \& Pereira, R. (2006). Financial development and the cash flow sensitivity of cash. Journal of Financial and Quantitative Analysis, 41(4), 787-807.

Love, I. (2003). Financial development and financing constraints: international evidence from the structural investment model. Review of Financial Studies, 16(3), 765-791.

Musso, P. \& Schiavo, S. (2008). The impact of financial constraints on firm survival and growth. Journal of Evolutionary Economics, 18(2), 135-149.

Silva, F. \& Carreira, C. (2012). Measuring firms' financial constraints: A rough guide. Notas Económicas, 36, 23-46.

Starkey, R. (2010). Financial system development and economic growth in Selected African countries: Evidence from a panel cointegration analysis, Master's Thesis, Rhodes University, Grahamstown. 